\title{
BMJ Open Changes in demand for emergency ambulances during a nationwide lockdown that resulted in elimination of COVID-19: an observational study from New Zealand
}

\author{
Bridget Dicker (D) , 1,2 Andrew Swain (D) , 1,3 Verity Frances Todd (D) ,,2 \\ Bronwyn Tunnage (D) , ${ }^{1,2}$ Emma McConachy (D) , ${ }^{1}$ Haydn Drake (D) , \\ Michelle Brett (D) ,2 Dan Spearing (D) ,2 Graham John Howie (D) ${ }^{1,2}$
}

To cite: Dicker B, Swain A, Todd VF, et al. Changes in demand for emergency ambulances during a nationwide lockdown that resulted in elimination of COVID-19: an observational study from New Zealand. BMJ Open 2020;10:e044726. doi:10.1136/ bmjopen-2020-044726

\section{- Prepublication history and} additional material for this paper is available online. To view these files, please visit the journal online (http://dx.doi.org/10. 1136/bmjopen-2020-044726)

Received 13 September 2020 Revised 01 December 2020 Accepted 08 December 2020

Check for updates

(c) Author(s) (or their employer(s)) 2020. Re-use permitted under CC BY-NC. No commercial re-use. See rights and permissions. Published by BMJ.

${ }^{1}$ Paramedicine Department, Auckland University of Technology, Auckland, New Zealand

${ }^{2}$ Clinical Audit and Research, St John New Zealand, Auckland, New Zealand

${ }^{3}$ Wellington Free Ambulance, Wellington, New Zealand

Correspondence to

Professor Bridget Dicker;

bridget.dicker@stjohn.org.nz

\section{ABSTRACT}

Objective To examine the impact of a 5-week national lockdown on ambulance service demand during the COVID-19 pandemic in New Zealand.

Design A descriptive cross-sectional, observational study. Setting High-quality data from ambulance electronic clinical records, New Zealand.

Participants Ambulance records were obtained from 588690 attendances during pre-lockdown (prior to 17 February 2020) and from 36238 records during the lockdown period (23 March to 26 April 2020).

Main outcome measures Ambulance service utilisation during lockdown was compared with pre-lockdown: (a) descriptive analyses of ambulance events and proportions of event types for each period, (b) absolute rates of ambulance attendance (event types/week) for each period.

Results During lockdown, ambulance patients were more likely to be attended at home and less likely to be aged between 16 and 25 years. There was a significant increase in the proportion of lower acuity patients (Status 3 and Status 4$)$ attended $(p<0.001)$ and a corresponding increase in patients not transported from scene $(p<0.001)$. Road traffic crashes $(p<0.001)$ and alcohol-related incidents $(p<0.001)$ significantly decreased. There was a decrease in the absolute number of weekly ambulance attendances (ratio (95\% Cl), 0.89 (0.87 to 0.91), $p<0.001$ ), attendances to respiratory conditions $(0.74(0.61$ to 0.86$)$, $\mathrm{p}=0.01)$, and trauma (0.81 (0.77 to 0.85), $\mathrm{p}<0.001)$. However, there was a significant increase in ambulance attendances for mental health conditions (1.37 (1.22 to 1.51), $p=0.005$ ).

Conclusions Despite the relative absence of COVID-19 in the community during the 5-week nationwide lockdown, there were significant differences in ambulance utilisation during this period. The lockdown was associated with an increase in ambulance attendances for mental health conditions and is of concern. In considering future lockdowns, the potential implications on a population's mental well-being will need to be seriously considered against the benefits of elimination of virus transmission.
Strengths and limitations of this study

- Ambulance utilisation during the lockdown period was able to be studied in an environment with minimal presence of COVID-19 in the community.

- Our study is a retrospective cohort study of over 600000 ambulance records.

- The study is national, encompassing ambulance services across the whole of New Zealand.

- The 'Clinical Impressions' are relatively broad categories, clustering some disparate diseases together.

Data was analysed retrospectively, and this unavoidably influences the interpretation of results.

\section{INTRODUCTION}

Between December 2019 and January 2020, the first cases of COVID-19 were detected in Wuhan, China. ${ }^{1}$ By the end of January 2020 more than 7818 cases were reported worldwide. ${ }^{2}$ In New Zealand, a high-income island nation in the South Pacific, the first cases of the COVID-19 virus were detected on 28 February 2020 and peaked at 89 new cases per day on 5 April $2020 .^{3}$ A stringent public health intervention strategy was successfully used to prevent the community spread of the virus in New Zealand. This required all residents to stay at home other than for essential purposes. All businesses, schools and facilities were closed from 23 March until 27 April. Citizens were required to isolate within domestic 'bubbles'; $2 \mathrm{~m}$ physical distancing was stipulated outside the home boundary. Primary healthcare consultations were undertaken by phone or video, with prescriptions being dispatched to pharmacies close to the patient. Governmental messaging urged citizens to avoid hospitals where possible. ${ }^{4}$ There was widespread compliance with the 'Stay at Home' mandate and this 
nationwide lockdown, which included border closures, effectively curtailed community transmission of the virus. As of the end of the lockdown period (27 April 2020), New Zealand-with a population of 4.8 million-had 1476 COVID-19 cases and 19 deaths; by comparison, Ireland-a country of a similar population ( 4.9 million $)$ - experienced 20253 cases and 1190 deaths. ${ }^{45}$

Lockdowns can slow or even eliminate a viral pandemic; however, enforced lockdowns may also have profound effects on healthcare utilisation by the population. ${ }^{6}$ In particular, there is concern that the public may be fearful of contracting infection by attending a medical facility or general practitioner. In England, presentations to emergency departments decreased by $25 \%$ during the second week of their lockdown. ${ }^{7}$ Similarly, Austria recorded a decrease in admissions for acute coronary syndromes during their quarantine/lockdown period. ${ }^{8}$ In areas of high COVID-19 prevalence, there may have been reluctance or advice not to present to emergency departments due to an overwhelmed health system..$^{9}$ In the above examples, it is difficult to determine whether it is the effects of the lockdown, or the presence of COVID-19 in the community, which changes the normal demand for health support.

If the pandemic response changes healthcare utilisation by the public, what impact does this have on ambulance services? The progressive eradication of COVID-19 for a period of 3 months in New Zealand gave us the opportunity to study the impacts of a nationwide and border lockdown on ambulance service utilisation. The objective of this study was to examine the impact of a 5 -week national lockdown on ambulance service demand during the COVID-19 pandemic in New Zealand. This will inform health authorities of the likely impact of future pandemic lockdowns on ambulance services.

\section{METHODS \\ Design}

This was a descriptive, cross-sectional study of ambulance attendances within New Zealand during pre-lockdown and lockdown periods. The study was performed at a national level.

\section{The data}

Details for all events attended by New Zealand road ambulances (St John and Wellington Free Ambulance services) are recorded electronically by paramedics at the scene. Data for this study were extracted retrospectively from this data set.

\section{Inclusion and exclusion criteria}

The pre-lockdown data set included all ambulance attendances during the periods 1 March 2018 (when clinical data went electronic) to 30 November 2018, and 1 July 2019 to 16 February 2020, a total of 72 weeks. Data from 1 December 2018 to 30 June 2019 was not available due to ambulance service industrial action during this time.
The nationwide lockdown included all ambulance attendances during the 5-week period, 23 March 2020 to 26 April 2020.

\section{Population demographics}

Variables included: sex, age, ethnicity, rurality and location type (aged care facility, healthcare facility, public/ other, home). Three ethnicity groupings were analysed: Māori (the indigenous population of New Zealand), Pacific Peoples (people predominantly from South Pacific Islands including Samoa, Cook Islands, Tonga and Niue) and European/others. All other ethnicities, which comprised less than $5 \%$ of the data set, were included within the European/others cohort.

Rurality (urban vs rural) was determined by Statistics New Zealand 2013 Census Meshblocks aligned to the address/ location of the event. ${ }^{10}$ For the purposes of this study, urban and rural were defined by the following Statistics New Zealand Meshblock descriptors: urban included 'Main Urban Area' and 'Secondary Urban Area', while rural included 'Minor Urban Area', 'Rural Centre' and 'Other Rural'.10

\section{Clinical presentation and disposition}

Clinical Impression is the ambulance clinician's working diagnosis. For the purposes of this study, over 600 possible Clinical Impressions were up-grouped into generic categories to enable an overarching descriptive analysis. The grouping of these Clinical Impressions is available as supplementary data, online supplemental table 1. Mechanism of injury is recorded only for trauma cases. Patient disposition variables included transport versus non-transport with reasons. Final patient acuity is defined by the attending paramedics using five assigned Status Codes (1-immediate threat to life, 2-potential threat to life, 3-unlikely threat to life, 4-no threat to life, 0 -dead). Status 3 and Status 4 patients were considered low acuity.

\section{Patient and public involvement}

This research did not draw on patient or public involvement. Patients were not invited to comment on the study design and were not consulted to develop patient relevant outcomes or interpret the results. Research findings will be widely disseminated through public, official, personal and social communication tools.

\section{Statistical analyses}

The distribution of variables within each time period was described as totals and percentages of total numbers. Pearson's $\chi^{2}$ test and the z-test for column proportions were used to compare nominal values. Statistically significant differences were considered to be meaningful only if they differed during lockdown compared with prelockdown by more than $1.5 \%$. Effect size was calculated using the Cohen's $d$ test. Effect size was considered small $0.2-0.4$, medium $0.5-0.7$ and large $\geq 0.8$.

The two-tailed independent samples t-test was used to compare mean changes in ambulance attendances 
Table 1 Descriptive analysis, demographics ( $n=624928)$, changes in distribution

\begin{tabular}{|c|c|c|c|c|}
\hline & Pre-lockdown (PL) n=588690 & Lockdown (LD) n=36238 & $\Delta \%=$ LD - PL & ${ }^{*} \mathbf{P}$ value \\
\hline Sex & & & & 0.01 \\
\hline Female & 309991 (52.7\%) & $19326(53.4 \%)$ & $0.7 \%$ & \\
\hline Age (years) & & & & $<0.001$ \\
\hline $0-5$ & $27258(4.6 \%)$ & $1326(3.7 \%)$ & $-1.0 \%$ & \\
\hline $16-25$ & $57119(9.7 \%)$ & $2875(7.9 \%)$ & $-1.8 \%$ & \\
\hline $26-45$ & $92530(15.7 \%)$ & $6201(17.1 \%)$ & $1.4 \%$ & \\
\hline $46-65$ & $122699(20.9 \%)$ & $7948(22.0 \%)$ & $1.1 \%$ & \\
\hline$>65$ & $267540(45.5 \%)$ & $16917(46.7 \%)$ & $1.3 \%$ & \\
\hline Ethnicity & & & & 0.07 \\
\hline Pacific Peoples & $27709(5.4 \%)$ & $1623(5.2 \%)$ & $-0.2 \%$ & \\
\hline Rurality & & & & 0.25 \\
\hline Rural & $129002(22.5 \%)$ & $7948(22.3 \%)$ & $-0.3 \%$ & \\
\hline Urban & $444054(77.5 \%)$ & $27774(77.8 \%)$ & $0.3 \%$ & \\
\hline Location & & & & $<0.001$ \\
\hline Aged care facility & $33334(5.7 \%)$ & $1689(4.7 \%)$ & $-1.0 \%$ & \\
\hline Healthcare facility $†$ & $51831(8.8 \%)$ & 1404 (3.9\%) & $-4.9 \%$ & \\
\hline Public/other & 111771 (19.0\%) & $2930(8.1 \%)$ & $-10.9 \%$ & \\
\hline Home & 390934 (66.5\%) & 30166 (83.4\%) & $16.9 \%$ & \\
\hline
\end{tabular}

${ }^{*} \mathrm{P}<0.05$ is significant; $\chi^{2}$ test for nominal values. Independent t-test for continuous values. Missing values were $<3 \%$ for all variables except ethnicity (14.6\%), the proportion of missing values for this variable was similar across both pre-lockdown and lockdown periods. Percentages may not add to $100 \%$ due to rounding.

†Healthcare facility refers to non-hospital treatment localities such as a general practice clinic.

per week. Data presented are: mean, SD and ratios with $95 \%$ CIs. Data analysis was performed using IBM SPSS (V.26.0). A p value of $<0.05$ was considered statistically significant.

\section{RESULTS}

Overall, 624928 patients were attended by New Zealand Ambulance services and were included in the study. These were 588690 patients during the pre-lockdown period and 36238 during the lockdown period.

\section{Demographics}

Compared with the pre-lockdown period, there were statistically significant differences in the distribution of cases during the lockdown (supplementary data, online supplemental table 2). Those variables which differed during lockdown compared with pre-lockdown by more than $1.5 \%$ included a lower proportion of patients attended who were in the 16-25 years age group (table 1 ). There were no statistical differences in the proportions of patients according to ethnicity or rurality.
During lockdown there was a large increase in the proportion of patients attended in their homes and a decrease in the proportion of patients attended in other locations (healthcare, public/other) (table 1).

\section{Clinical presentation}

Compared with pre-lockdown, there was a statistically significant difference in the distribution of Clinical Impressions during the lockdown period (supplementary data, online supplemental table 3). Respiratory conditions and trauma were the Clinical Impressions whose proportions of patients decreased by more than $1.5 \%$ (table 2).

The proportion of incidents with suspected alcohol involvement decreased during lockdown (table 2).

When comparing the mechanisms of injury to the prelockdown period, there was a decrease in the proportion of road traffic crashes, with a corresponding increase in the proportion of falls and other trauma.

\section{Patient disposition}

During lockdown, there were significant changes in patient disposition. The proportion of patients that were 
Table 2 Descriptive analysis, clinical impression $(n=624928)$, changes in distribution

\begin{tabular}{|c|c|c|c|c|}
\hline & Pre-lockdown (PL) n=588690 & Lockdown (LD) $n=36238$ & $\Delta \%=$ LD-PL & ${ }^{*} \mathbf{P}$ value \\
\hline Clinical Impression & & & & $<0.001$ \\
\hline Abdominal pain & $45479(7.8 \%)$ & 3240 (9.1\%) & $1.3 \%$ & \\
\hline Cardiac & $61083(10.4 \%)$ & $4082(11.4 \%)$ & $1.0 \%$ & \\
\hline Collapse & $27296(4.7 \%)$ & $1516(4.2 \%)$ & $-0.4 \%$ & \\
\hline Haemorrhage & $10932(1.9 \%)$ & $717(2.0 \%)$ & $0.1 \%$ & \\
\hline Infection & $37374(6.4 \%)$ & $2369(6.6 \%)$ & $0.3 \%$ & \\
\hline Mental health & $13966(2.4 \%)$ & $1318(3.7 \%)$ & $1.3 \%$ & \\
\hline Metabolic & $28580(4.9 \%)$ & $1616(4.5 \%)$ & $-0.4 \%$ & \\
\hline Other medical & $76741(13.1 \%)$ & $4875(13.6 \%)$ & $0.5 \%$ & \\
\hline Pain & $68678(11.7 \%)$ & $4333(12.1 \%)$ & $0.4 \%$ & \\
\hline Poisoning & $18519(3.2 \%)$ & $802(2.2 \%)$ & $-0.9 \%$ & \\
\hline Respiratory & $67144(11.5 \%)$ & 3449 (9.6\%) & $-1.8 \%$ & \\
\hline Stroke & $13652(2.3 \%)$ & $916(2.6 \%)$ & $0.2 \%$ & \\
\hline Trauma & $117127(20.0 \%)$ & $6535(18.3 \%)$ & $-1.7 \%$ & \\
\hline Did alcohol contribute? & & & & $<0.001$ \\
\hline No & $417011(93.3 \%)$ & $25493(95.2 \%)$ & $1.9 \%$ & \\
\hline Yes & $30076(6.7 \%)$ & $1300(4.9 \%)$ & $-1.9 \%$ & \\
\hline Mechanism of injury & & & & $<0.001$ \\
\hline Assault & $8924(6.0 \%)$ & $445(5.7 \%)$ & $-0.3 \%$ & \\
\hline Fall & 75225 (50.8\%) & 4603 (58.9\%) & $8.0 \%$ & \\
\hline Other trauma & $39278(26.6 \%)$ & 2254 (28.8\%) & $2.3 \%$ & \\
\hline Road traffic crash & 24534 (16.6\%) & 518 (6.6\%) & $-10.0 \%$ & \\
\hline
\end{tabular}

${ }^{*} \mathrm{P}<0.05$ is significant; $\chi^{2}$ test for nominal values. Independent $t$-test for continuous values. Missing values were $<3 \%$ for all variables except did alcohol contribute? (27.1\%) and mechanism of injury (15.1\%, across all trauma cases), the proportion of missing values for these variables was similar across both pre-lockdown and lockdown periods. Percentages may not add to $100 \%$ due to rounding.

Table 3 Descriptive analysis, patient disposition and acuity $(n=624928)$ changes in distribution

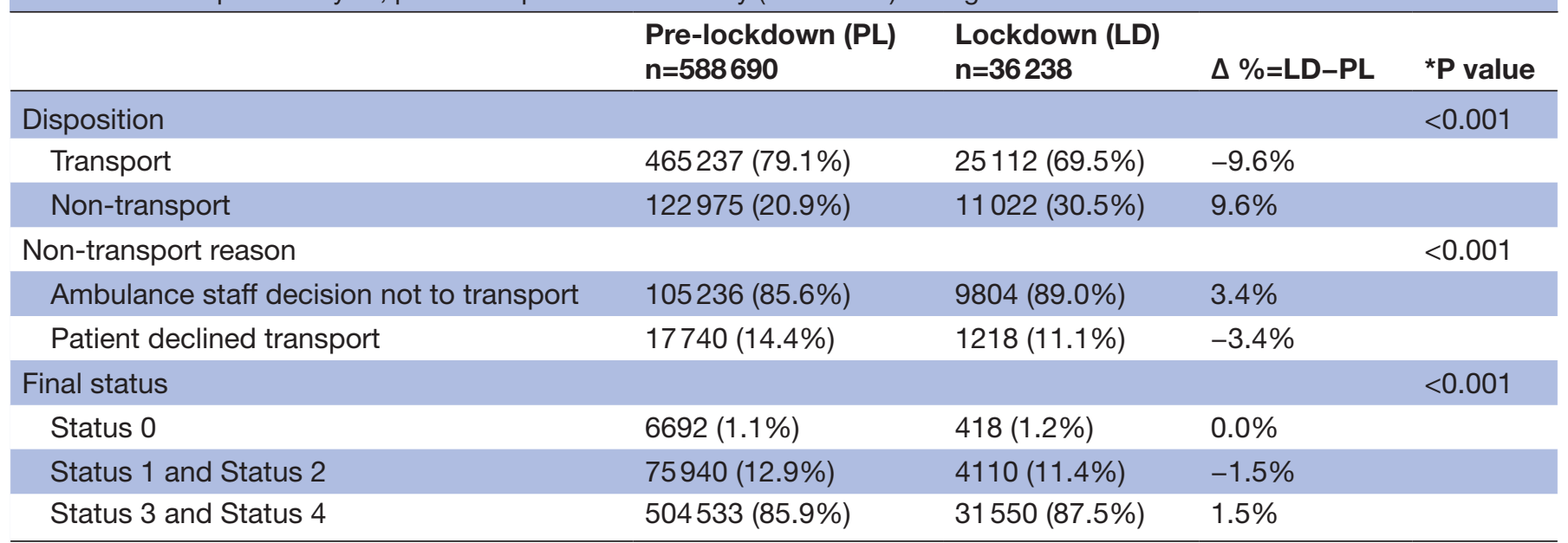

${ }^{*} \mathrm{P}<0.05$ is significant; $\chi^{2}$ test for nominal values. Independent t-test for continuous values. Missing values were $<3 \%$ for all variables. Percentages may not add to $100 \%$ due to rounding. 


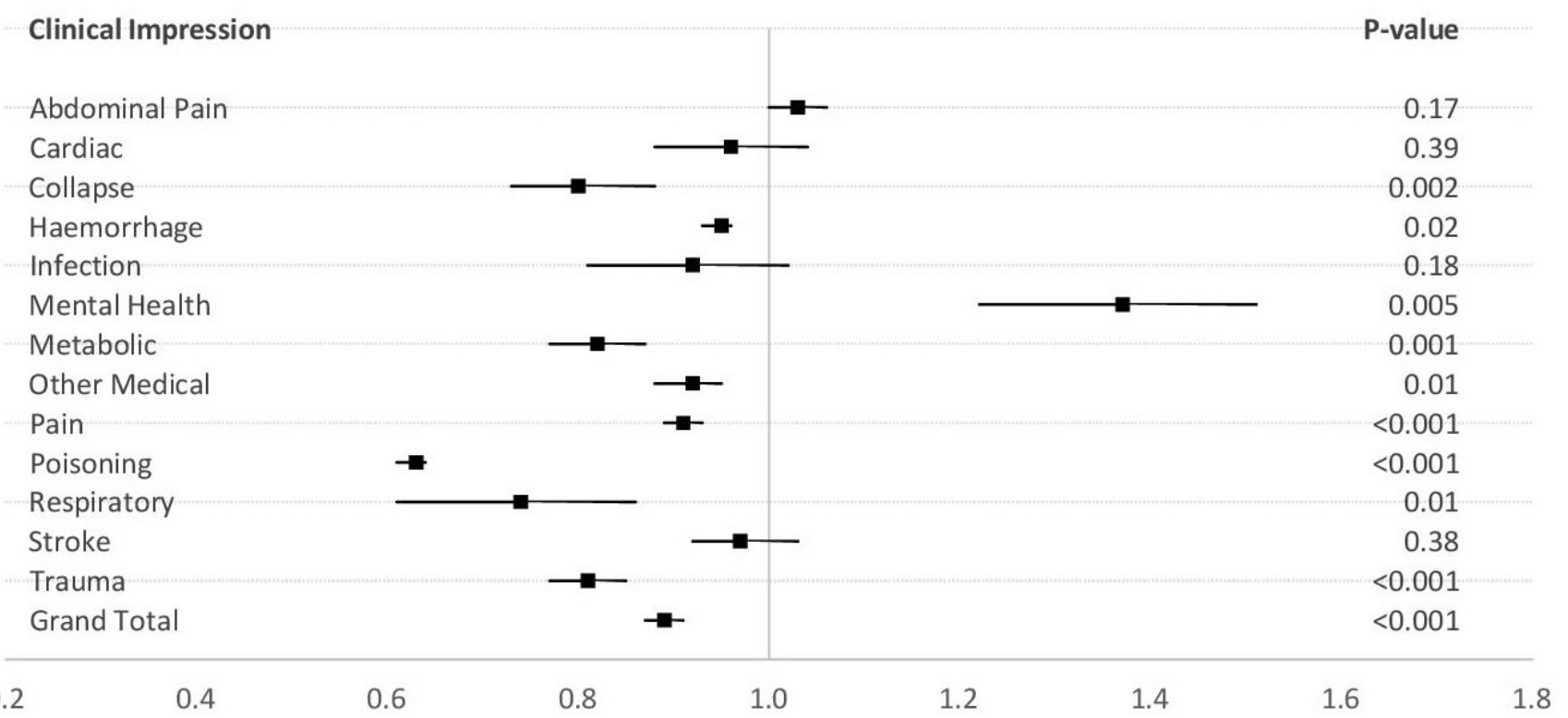

0.2

0.4

$0.6-0.8$

1.0

1.2

1.4

Figure 1 Changes in absolute event rates per week during the lockdown compared with pre-lockdown period. $\mathrm{P}<0.05$ is significant; Independent t-test for continuous values. Missing values were $<3 \%$ for all variables.

deemed by ambulance staff not to require transport by ambulance increased, as did the proportion of lowest acuity patients (Status 3 and Status 4) (table 3 and supplementary data, online supplemental table 4 ).

\section{Event rates, mean number of attendances per week}

During lockdown, there was an overall decrease in the absolute number of incidents per week attended by ambulance and this involved almost all Clinical Impressions, although the decreases seen in cardiac, infection and stroke rates were non-significant. The rate for abdominal pain rose but was statistically non-significant (figure 1 and online supplemental table 5). For all the Clinical Impressions that exhibited statistically significant decreases, this correlated with effect sizes in the 'medium to large' range, by the Cohen's $d$ test (supplementary data, online supplemental table 5).

During the lockdown there was a significant increase with a large effect size in the mean weekly rate of attendance to patients with clinical presentations of mental health (figure 1 and supplementary data, online supplemental table 5).

Attendances at traumatic events were significantly decreased during the lockdown period, as were rates of attendance at incidents where alcohol was considered a contributing factor (figure 2 and supplementary data, online supplemental table 6 ). Weekly rates

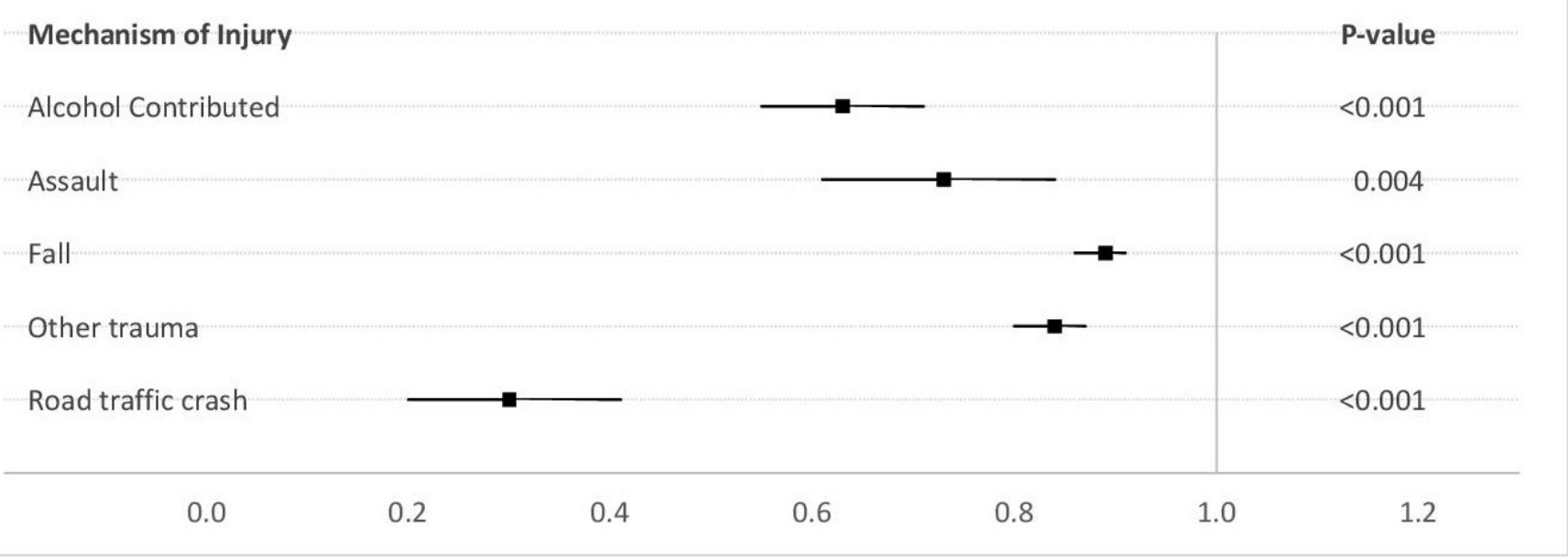

Figure 2 Changes in Mechanism of Injury during the lockdown compared to pre-lockdown period. $\mathrm{P}<0.05$ is significant; Independent t-test for continuous values. Missing values were Mechanism of Injury (15.1\%, of Trauma cases) and whether Alcohol Contributed (27.1\%). Missing data for these variables was similar across both Pre-Lockdown and Lockdown periods. 
for all traumatic mechanisms of injury fell during lockdown.

\section{DISCUSSION}

There was a striking difference in ambulance service utilisation during a national lockdown of the population in New Zealand. The lockdown lasted 5 weeks where everyone except essential workers were required to isolate at home and only permitted to leave home for exercise within the local area while maintaining social distancing. ${ }^{11}$ There were notable changes in demographics, patient acuity, disposition and mechanism of injury. Absolute numbers of weekly patient attendances diminished alongside attendances to a number of pertinent Clinical Impressions. There was a stark and significant increase in absolute numbers of ambulance attendances for mental health conditions. During the lockdown there was a reduction in the proportion of people aged 16-25 years attended and an increase in ambulance attendances to the home location. A reduction in ambulance attendance to young people may be attributable to a potential decrease in usual injuries, recreational or accidental, as they may have been less exposed to sport or risk. Young people were also less exposed to endemic community infections through the closure of schools, workplaces, bars and night clubs, and confinement within the home. Studies have demonstrated an increased frequency of illness in association with school attendance. ${ }^{12-14}$ Any going out at night, gathering and socialising was prevented during lockdown. Additionally, increased hygiene practices such as handwashing could be expected to reduce the frequency of community-acquired illnesses. ${ }^{1516}$

A greater proportion of calls were to events located at home, with a lesser proportion in public places. This likely reflects the government instruction for the population to stay at home. Lockdown did not appear to alter utilisation of ambulance care by different ethnic groups or the rural sector.

The proportion of high-acuity work decreased, as did the proportion of patients transported to an emergency department. This could be due to reluctance to transport patients to hospitals which might already be stretched with COVID-19 work, or perhaps patients were reluctant to be transported to facilities where they thought they might become infected themselves. It is noteworthy that during the total lockdown the number of actual COVID-19 cases in New Zealand was relatively small and hospital capacity never became an issue. In our study, the reason for non-transport of patients was primarily at the recommendation of the attending staff, inferring that the patients did not require ambulance transport, rather than patients declining to be transported. Interestingly, this study indicates that during lockdown a greater proportion of low-acuity patients were requesting ambulance service attendance, and that many of them were not acutely unwell enough to require transport to a medical facility by ambulance. Perhaps this could also be a manifestation of decreased access to primary care services. General practice consultations were undertaken by phone or video during lockdown, and this could have presented a barrier to access for those unfamiliar with and/or without access to this technology.

There was a reduction in road traffic crashes, which may demonstrate compliance with the strict restrictions on travel that were imposed during lockdown. This was evident through Google Mobility data that indicated an average $88 \%$ reduction in the use of recreational and retail spaces during lockdown compared with baseline. ${ }^{17}$ Supporting this, Ministry of Transport data demonstrated a reduction of retail petrol and diesel sales by $80 \% .^{18}$ Also in line with our findings of an absolute reduction in trauma, there were 34 fewer fatal road traffic crashes during the lockdown compared with the same period in 2019. ${ }^{18}$ The decrease in incidents involving alcohol is noteworthy. A recent survey conducted by the Health Promotion Agency indicated that during lockdown $47 \%$ of people drank the same as normal, while $34 \%$ drank less than normal with the remaining $19 \%$ drinking more than normal. ${ }^{19}$ The majority of survey respondents who drank less than normal attributed this decrease to the closure of bars and night clubs and an inability to socialise.

During the lockdown period, ambulance use diminished for almost every type of medical or traumatic event. In one sense, the requirement to 'Stay at Home' may have had a protective effect on the New Zealand population. Recent statistics indicate a decrease in weekly mortality in the first 23 weeks of 2020 compared with the same time in the preceding 3 years. ${ }^{20}$ Attendance to respiratory conditions declined, which may be related to a decrease in transmission of usual airborne illnesses through decreases in social contact. Data collected from the New Zealand FluTracking website indicated an almost $10 \%$ decrease in self-reported influenza-like illness in the week ending 19 April 2020 compared with the same period in $2019 .^{21}$ A reduction in the level of nitrous oxide in Asian and European countries indicative of a reduction in air pollution has been noted during periods of lockdown; such improvements in air quality may also have a protective effect from coryzal-type illness. ${ }^{22}$ This reduction in air pollution during lockdown was also found in New Zealand, with a $41 \%$ reduction in daily carbon emissions during the 5 -week period. ${ }^{23}$

The one type of ambulance presentation that dramatically increased, both in proportion of attendances and in absolute rates per week, was mental health conditions. These may have been triggered by the imposition of social isolation with its restriction in human-to-human contact. ${ }^{24}{ }^{25}$ Additionally, there was the impact of uncertainty directly related to the pandemic: the fear of contracting COVID-19, or of losing friends and family through the virus, plus for many, fear of financial difficulties, loss of employment or the family home. In New Zealand, the COVID-19 pandemic response was associated with the most severe restrictions on social freedoms in modern history, along with significant economical 
impacts. Although these measures were effective in eliminating community transmission of COVID-19, it appears to have affected the mental health of some citizens. Pandemic-induced increases in psychological distress have been reported in both Australia and the United Kingdom and more so among women, younger age groups and those living with young children. ${ }^{24}{ }^{26}$ Those with pre-existing health inequalities such as older age and low income were at increased risk. ${ }^{26}$ Lockdown has also been associated with a significant negative impact on the well-being of children and adolescents. ${ }^{27}$ This impact is of particular concern, because routines and social interaction are critical factors for normal psychological development in these age groups.

In contrast to many other developed nations, New Zealand's lockdown restrictions were enforced early so that the health system was not overwhelmed and it experienced a reduction in overall volume. There was no significant rise in referrals to secondary mental health services during lockdown, though this was hardly surprising considering the reduction in primary care consultations (which are the predominant referral route to secondary mental health services) ${ }^{28}$ However, while there were physical restrictions on access to primary care during lockdown, no such restrictions existed for ambulance service utilisation, which saw a dramatic increase in attendances for mental health conditions.

When planning for additional periods of COVID-19 lockdown or for future pandemics, ambulance services should prepare to meet this increase in mental ill-health. The alteration in ambulance service demand between pre-lockdown and lockdown conditions is unlikely to be due to community COVID-19 itself as the number of cases was minimal in New Zealand at the time of the lockdown. This study represents a unique analysis of ambulance service demand under the conditions of strict lockdown.

\section{Limitations}

Our 'Clinical Impressions' are relatively broad categories, clustering together some disparate disease conditions; For example, asthma, chronic obstructive pulmonary disease and chest infections are all categorised as 'Respiratory Conditions'. However, this provided a broad overview of ambulance utilisation and was applied consistently across both pre-lockdown and lockdown periods. Similarly, our current data does not differentiate between common mental health presentations, such as depression, anxiety, psychological distress, that will be the task of a separate publication. In addition, the poisoning category includes intentional poisoning and alcohol intoxication. This categorisation may remove some potential suicide risk or self-harm cases from the mental health group, and the reduction in alcohol consumption during lockdown may be obscuring smaller increases in other types of poisoning within this broad Clinical Impression.

Emergency call centre data was not included within this study. We only looked at ambulance attendance to patients. As such, it is unknown if there were changes in the frequency and/or acuity of calls made to the emergency services during the lockdown period.

The data set has not been adjusted for seasonality or population growth. The broad Clinical Impressions and population ages analysed meant that any such adjustment could be nuanced: changes in different Clinical Impressions may differ by season, and changes in population growth in accordance with age may also impact ambulance utilisation differently (eg, older populations have a higher utilisation of the ambulance service). Future studies will focus on single Clinical Impressions and their subcategories, and these will be adjusted based on seasonality and population growth accordingly. Potential factors to adjust for overall demand have been included within the supplementary data (supplementary data, online supplemental table 7).

Lockdown was instituted less than a month after COVID-19 reached New Zealand. As a result, data has had to be analysed retrospectively and this unavoidably influences the interpretation of results.

Three of our variables had more than $10 \%$ missing data in the categories of ethnicity, alcohol contribution and mechanism of injury. Although the proportion of missing data was not different between pre-lockdown and lockdown periods, this may have biased analysis of these categories of data.

\section{CONCLUSIONS}

A nationwide lockdown during the COVID-19 pandemic proved to be very effective in controlling and eliminating the spread of the COVID-19 in New Zealand, but it significantly altered the pattern of demand on ambulance care. 'Stay at Home' orders led to a reduction in many types of ambulance call-out, notably respiratory conditions, trauma and incidents involving alcohol. In contrast, mental health conditions rose significantly during this period of pandemic uncertainty, relating especially to confinement at home, reduced social contact and loss of earnings for many. These changes occurred in the relative absence of COVID-19 in the community. In considering future lockdowns, the implications for the population's mental well-being need to be seriously weighed against the benefits of elimination of virus transmission within the community. Ambulance services need to be prepared for an increased caseload of mental ill-health, should further lockdowns occur.

Correction notice This article has been corrected since it first published. The provenance and peer review statement has been included.

Twitter Bridget Dicker @bridgetdicker and Haydn Drake @paramedickiwi

Acknowledgements We would like to thank the Clinical Audit and Research team at St John for their support of this study.

Contributors BD contributed to the study design, contributed to the literature review, conducted the analysis and was primarily responsible for the article preparation. GJH contributed to the literature review and to the interpretation of data and preparation of the paper. AS contributed to the study design, provided oversight of the project, interpretation of results and article preparation. VFT, BT, 
$\mathrm{EMC}, \mathrm{HD}, \mathrm{MB}$ and $\mathrm{DS}$ contributed to the study design, the literature review and to the interpretation of data and preparation of the paper.

Funding The authors have not declared a specific grant for this research from any funding agency in the public, commercial or not-for-profit sectors.

Competing interests None declared.

Patient consent for publication Not required.

Ethics approval Ethical approval for this study was provided by the Auckland University of Technology Ethics Committee (No. 20/151).

Provenance and peer review Not commissioned; externally peer reviewed.

Data availability statement No data are available. Data are not available in accordance with the ethics committee approval.

Supplemental material This content has been supplied by the author(s). It has not been vetted by BMJ Publishing Group Limited (BMJ) and may not have been peer-reviewed. Any opinions or recommendations discussed are solely those of the author(s) and are not endorsed by BMJ. BMJ disclaims all liability and responsibility arising from any reliance placed on the content. Where the content includes any translated material, BMJ does not warrant the accuracy and reliability of the translations (including but not limited to local regulations, clinical guidelines, terminology, drug names and drug dosages), and is not responsible for any error and/or omissions arising from translation and adaptation or otherwise.

Open access This is an open access article distributed in accordance with the Creative Commons Attribution Non Commercial (CC BY-NC 4.0) license, which permits others to distribute, remix, adapt, build upon this work non-commercially, and license their derivative works on different terms, provided the original work is properly cited, appropriate credit is given, any changes made indicated, and the use is non-commercial. See: http://creativecommons.org/licenses/by-nc/4.0/.

\section{ORCID iDs}

Bridget Dicker http://orcid.org/0000-0002-8151-7356

Andrew Swain http://orcid.org/0000-0002-8599-8820

Verity Frances Todd http://orcid.org/0000-0003-4786-8272

Bronwyn Tunnage http://orcid.org/0000-0002-6554-3634

Emma McConachy http://orcid.org/0000-0003-0619-6916

Haydn Drake http://orcid.org/0000-0003-0191-2258

Michelle Brett http://orcid.org/0000-0003-0053-0290

Dan Spearing http://orcid.org/0000-0002-9056-2263

Graham John Howie http://orcid.org/0000-0001-6907-8074

\section{REFERENCES}

1 Lau H, Khosrawipour V, Kocbach P, et al. The positive impact of lockdown in Wuhan on containing the COVID-19 outbreak in China. $J$ Travel Med 2020;27:taaa037.

2 World Health Organisation. Archived: WHO timeline - COVID-19, 2020. Available: https://www.who.int/news-room/detail/27-04-2020who-timeline---covid-19

3 epidemic-stats.com. Coronavirus statistics, 2020. Available: https:// epidemic-stats.com/coronavirus/new-zealand\#update-log

4 Wilson S. Pandemic leadership: lessons from New Zealand's approach to COVID-19. Leadership 2020;16:279-93.

5 Epidemic-stats.com. Coronavirus statistics, 2020. Available: https:// epidemic-stats.com/coronavirus/new-zealand

6 Atalan A. Is the lockdown important to prevent the COVID-9 pandemic? effects on psychology, environment and economyperspective. Ann Med Surg 2020;56:38-42.
7 Thornton J. Covid-19: A\&E visits in England fall by 25\% in week after lockdown. BMJ 2020;369:m1401.

8 Metzler B, Siostrzonek P, Binder RK, et al. Decline of acute coronary syndrome admissions in Austria since the outbreak of COVID-19: the pandemic response causes cardiac collateral damage. Eur Heart $J$ 2020;41:1852-3.

9 Rosenbaum L. The untold toll-the pandemic's effects on patients without Covid-19. N Engl J Med 2020;382:2368-71.

10 Statistics New Zealand. 2013 census meshblock dataset, 2017. Available: http://www.stats.govt.nz/Census/2013-census/datatables/meshblock-dataset.aspx

11 Ministry of Health. COVID-19 alert system, 2020. Available: https:// covid19.govt.nz/covid-19/alert-system/alert-system-overview/\#alertlevel-4-\%E2\%80\%94-lockdown

12 Temte JL, Meiman JG, Gangnon RE. School sessions are correlated with seasonal outbreaks of medically attended respiratory infections: electronic health record time series analysis, Wisconsin 2004-2011. Epidemiol Infect 2019;147:e127.

13 Wald ER, Dashefsky B, Byers C, et al. Frequency and severity of infections in day care. J Pediatr 1988;112:540-6.

14 Fleming DW, Cochi SL, Hightower AW, et al. Childhood upper respiratory tract infections: to what degree is incidence affected by day-care attendance? Pediatrics 1987;79:55-60.

15 Luby SP, Agboatwalla M, Feikin DR, et al. Effect of handwashing on child health: a randomised controlled trial. Lancet 2005;366:225-33.

16 Nandrup-Bus I. Mandatory handwashing in elementary schools reduces absenteeism due to infectious illness among pupils: a pilot intervention study. Am J Infect Control 2009;37:820-6.

17 Google. Google COVID19 community mobilty reports, 2020. Available: https://www.google.com/covid19/mobility/

18 Ministry of Transport. COVID-19 transport indicators dashboard 1 may, 2020. Available: https://www.transport.govt.nz//assets/ Uploads/Report/covid-19-transport-indicators-dashboard-1-may.pdf

19 Ministry of Health. The impact of lockdown on health risk behaviours, 2020. Available: https://www.hpa.org.nz/researchlibrary/research-publications/the-impact-of-lockdown-on-healthrisk-behaviours

20 Wilson N, Mizdrak A, Summers J, et al. Weekly deaths declined in NZ's lockdown - but we still don't know exactly why: University of Otago, 2020. Available: https://blogs.otago.ac.nz/pubhealthexpert/ 2020/07/10/weekly-deaths-declined-in-nzs-lockdown-but-we-stilldont-know-exactly-why/

21 Ministry of Health. FluTracking, 2020. Available: https://info. flutracking.net/reports-2/new-zealand-reports/

22 Gautam S. COVID-19: air pollution remains low as people stay at home. Air Qual Atmos Health 2020:1-5.

23 Le Quéré C, Jackson RB, Jones MW, et al. Temporary reduction in daily global $\mathrm{CO}_{2}$ emissions during the COVID-19 forced confinement. Nat Clim Chang 2020;10:647-53.

24 Newby JM, O'Moore K, Tang S, et al. Acute mental health responses during the COVID-19 pandemic in Australia. PLoS One 2020;15:e0236562.

25 Mortazavi SS, Assari S, Alimohamadi A, et al. Fear, loss, social isolation, and incomplete grief due to COVID-19: a recipe for a psychiatric pandemic. Basic Clin Neurosci 2020;11:225-32.

26 Pierce M, Hope H, Ford T, et al. Mental health before and during the COVID-19 pandemic: a longitudinal probability sample survey of the UK population. Lancet Psychiatry 2020;7:883-892.

27 Imran N, Aamer I, Sharif MI, et al. Psychological burden of quarantine in children and adolescents: a rapid systematic review and proposed solutions. Pak J Med Sci 2020;36:1106.

28 Bandyopadhyay G, Meltzer A. Let us unite against COVID-19 - a New Zealand perspective. Ir J Psychol Med 2020;37:218-21. 